\title{
側弯症手術中の春髄モニタリングの電位変化について
}

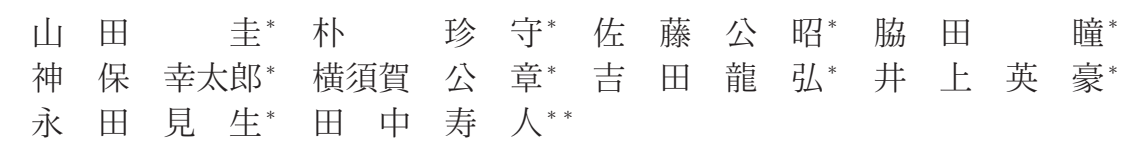

\section{Amplitude Changes of CMAP during Reductive Idiopathic Scoliosis Surgery at Anatomical Displacement of the Spinal Cord}

Kei Yamada*, Jin Soo Park*, Kimiaki Sato*, Hitomi Wakita*, Kotaro Jinbo*, Kimiaki Yokosuka*, Tatsuhiro Yoshida*, Hidetake Inoue*, Kensei Nagata*, and Hisato Tanaka**

【はじめに】特発性側弯症の術中矯正操作による経頭蓋電気刺激による筋誘発電位(CMAP) の变化と 術前の脊䯣の偏位との関連を検討した。【対象と方法】特発性側弯症 7 例に対し 1 例は胸腔鏡視下前方解 離術㧍よび後方矯正固定術(ISOLA 法)を，6例に ISOLA 法を施行した。脊䯣モニタリングは CMAPを 使用し，術前の春䯣の偏位の評価は鈴木法と Maruta の分類を使用した。【結果】derotation 操作で 3 例 が片側性に, Compression 操作で 3 例が片側性に CMAP の振幅が低下した。術後 5 例に大腿の知覚障害 を認めたが CMAP の変化との相関はなかった．Maruta 分類の reverse rotaion type 3 例で derotation 操作後, 片側性に CMAP が低下し術後大腿の知覚障害を認めた。【考察】 reverse rotation typeでは derotation 操作で脊䯣の血流障害を生じた可能性がある.

During spinal scoliosis surgery, compound muscle action potentials (CMAP) were recorded from distal upper and lower limb muscles following multipulse transcranial stimulation of the cortex. Seven patients, who were idiopathic scoliosis, were anaesthetized with propofol. One patient underwent anterior release of the thoracic spine and fusion by ISOLA method. The remaining six were reducted and fused by ISOLA method. The anatomical displacement of the spinal cord was classified into three groups according to Maruta's classification. Two cases were classified as over rotation type, the other two as under rotation type, and the remaining three as reverse rotation type. Three cases showed the decrease of amplitude of CMAP unilaterally after rod rotation maneuver. Three cases showed the decrease of amplitude of CMAP unilaterally after compression of spine. Five patients sustained sensory disturbance of the thigh after the operation. There was no relationship between the change of amplitude of CMAP and sensory disturbance after surgery. Three patients classified as reverse rotation type by Maruta's classification showed decreased CMAP amplitude after rod rotation maneuver and sustained thigh paresthesia after surgery. Rod rotaion maneuver may possibly have caused blood flow insufficiency of the spinal cord.

Key words : idiopathic scoliosis (特発性側弯症), compound muscle action potential (誘発筋電図), surgical treatment (手術治療)

\section{は じめに}

特発性側弯症の矯正固定術では春䯣モニタリングが 多用されている(1) (12)2 . 矯正直後にモニタリング波形 の変化を生じた場合は矯正操作の解除ないし緩和を行 う必要がある ${ }^{11}$. 本研究の目的は術前の春䯣の解剖学
的位置を評価し，特発性側弯症の矯正操作による経頭 蓋電気刺激による筋誘発電位 (CMAP) の変化, 術後 の神経症状との関連性を調查することである.

対象および方法

症例 と術式, 脊䯣の解剖学的評価：2005 年 7 月から

\footnotetext{
* 久留米大学整形外科 Department of Orthopaedic Surgery, Kurume University, Fukuoka, Japan

***田中病院 Tanaka's Hospital, Saga, Japan
} 


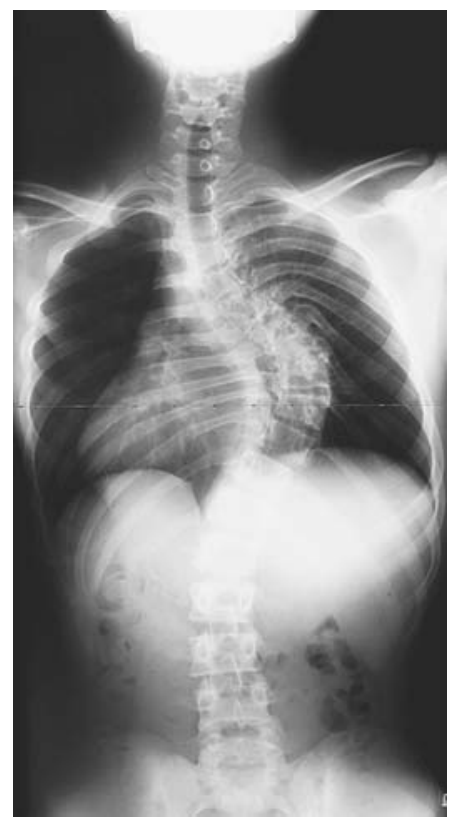

a

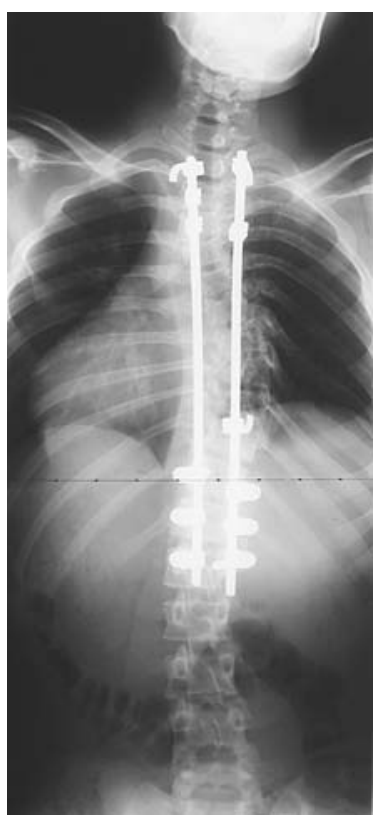

$\mathrm{b}$

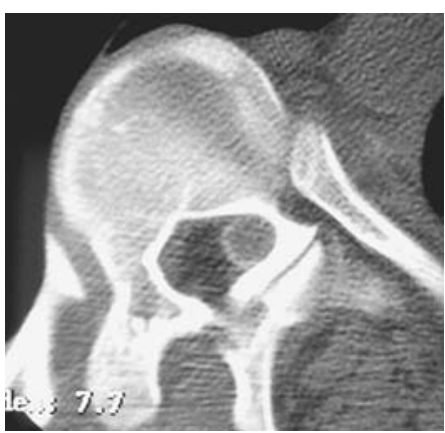

C

図 1：a）15歳 男性 King 分類 typeIV. 術前 Cobb 角 66 度

b ）胸腔鏡視下前方解離術および ISOLA 法を施行した。術後 Cobb 角 は 33 度で矯正率は50\%であった。

c ）術前の春䯣の偏位の状態は鈴木法で GradeIII, Maruta の分類で Reverse rotation typeであった。

2006 年 3 月まで当科で手術を施行した 7 例（男 1 例, 女 6 例）であった. 年齢は平均 14 歳で King の分類 の I 型が 3 例， II 型が 2 例，IV型が 1 例， V 型が 1 例 であった。術前 Cobb 角は平均 59 度であった。治療 は胸腔鏡視下胸椎前方解離術および後方矯正固定術 (ISOLA 法) を 1 例, ISOLA 法 ${ }^{8)}$ のみを 6 例に施行 した。手術時間は平均 299.5 分, 出血量は平均 $774.2 \mathrm{~g}$ であった。矯正率は平均 53.1\% で矯正操作は主に Derotation と Compression であった. 春髄の解剖学 的偏位の評価には鈴木法 ${ }^{3)}$ および Maruta ${ }^{6)}$ の分類を 使用した。

術中モニタリング：脊髄モニタリングには CMAPを 使用した。 CMAP モニターには日本光電社製ニュー ロパック MEB-2200を使用した。電気刺激装置は Degitimer 社製 Multipulse stimulator D185ないし 日本光電社製 SEN-4100 を，刺激電極は径 $15 \mathrm{~mm}$ 銀/ 塩化銀血電極, 導出電極は径 $6 \mathrm{~mm}$ の皿電極を使用し た。頭蓋刺激部位は $\mathrm{Cz}$ より前方 $2 \mathrm{~cm}$ 側方 $3 \mathrm{~cm}$ の大
脳運動野とした。CMAPは，上肢は短母指外転筋， 下肢は前脛骨筋から導出した。矯正操作前の最初の CMAP の振幅を $100 \%$ とし経時的に振幅の变化をパー センテージで記録した。 CMAP の振幅がコントロー ルの 50\%以上の低下ないし波形の多相化が認められ た場合，術者にアラームを発信した。麻酔は propofoll による全身麻酔を行った。刺激条件は Train 回数が 5 回, 刺激間隔は 3.2 3.5msec, 刺激電 圧は 250〜500V, Filtering は 100〜 1000 Hz とした。

これら 7 例の特発性側弯症について, 術前の春䯣の 偏位と矯正率, 術中の CMAP の振幅变化, 術後神経 症状との関連性を検討した。

結果

矯正操作後の CMAP の変化と術後神経症状： Derotation 後に 1 例が両側性に CMAP の振幅が低 下， 3 例が片側性に振幅が低下していた. Compression 操作後に 3 例が片側性に振幅が低下していた。手 
術終了時には 4 例で振幅が増大しており，2 例で振幅が 低下していた。術後大腿の感覚障害（paresthesia）を 5 例に認めたが CMAP の振幅の変化との関連性は不明 であった。

術前脊䯣の解剖学的評価と術後神経症状：Maruta ら ${ }^{6)}$ は頂椎レベルでの脊柱管内での脊䯣の回旋の状態 を Over-rotation type, Under-rotation type, Reverse-rotation typeの 3 つに分類している. Overrotation type は 2 例, Under-rotation type は 2 例 そして, Reverse-rotation type は 3 例であった。 Maruta の Over-rotation type 2 例中 1 例で左大腿 部痛を認めた. Under-rotation type 2 例中 1 例に両 側大腿殿部知覚鈍麻, 左下肢脱力感を生じていた.

Reverse-rotation type 3 例中 3 例に両側大腿痛ない ししびれを生じていた. 鈴木 ${ }^{3)}$ は頂椎の春柱管の凹側 を3 分割しそこに位置する脊䯣の中心によって Grade 分類している. Grade II が 6 例で，GradeIII が 1 例であった. GradeIII 1 例では両側大腿痛, Grade II の 6 例中 4 例に大腿部のしびれないし疼痛を認めて いた.

矯正率および術前春骾の偏位と矯正操作後の CMAP
の変化 : 矯正率による CMAP の変化との関連はなかっ た。鈴木法では明らかな grade 別で CMAP の振幅の 变化の差は認められなかった。 Marutaの分類の Reverse rotation type 3 例では 3 例とも derotation 後 に片側の CMAP の振幅が低下しており, Under rotation type 2 例では 2 例とも derotation 後に両側の CMAP の振幅が増大していた。

症例

症例 $1 ： 15$ 歳 男 King 分類 ${ }^{4}$ type 4 である (図 1a). 術前の春髄状態は鈴木の分類 ${ }^{3)}$ で gradeIII, Maruta の分類で reverse rotation type であった（図 1c). 術前 Cobb 角 66 度に対して胸腔鏡視下前方解離術お よび ISOLA 法を施行した（図 1b)。術後 Cobb 角は 33 度，矯正率は 50\%であった。 derotation 操作後 CMAP の低下はなかった（図 2，3）。 Derotation 後 20 分で左の CMAP がほぼ消失. 5 分間経過を見た が改善せず Wake up testを施行した。覚醒前に CMAP は改善した。最終時は振幅が増大していた (図 $2 ， 3$ ). 術後両側の大腿痛を認めた。
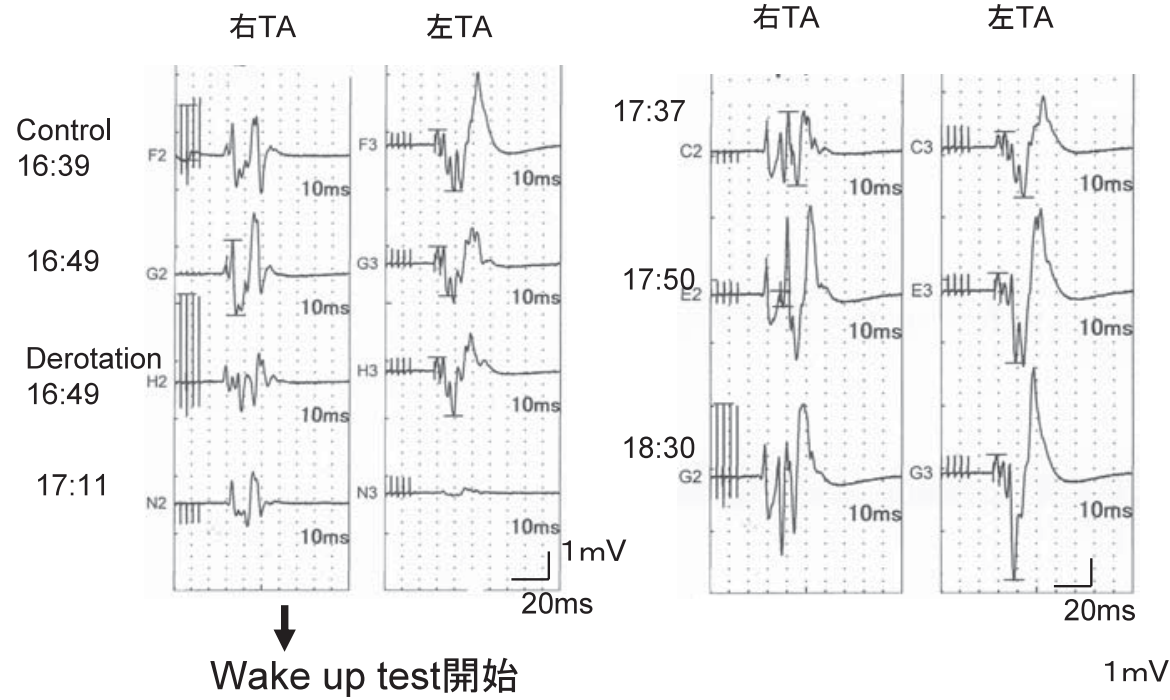

図 2：derotation 操作直後は有意な CMAP の振幅の低下は認めていなかった. Derotation 後 20 分で左側の前脛骨筋（TA）の CMAP が低下した. 改善ないため Wake up testを施行した。矯正操作を解除することなく 振幅は改善した。 


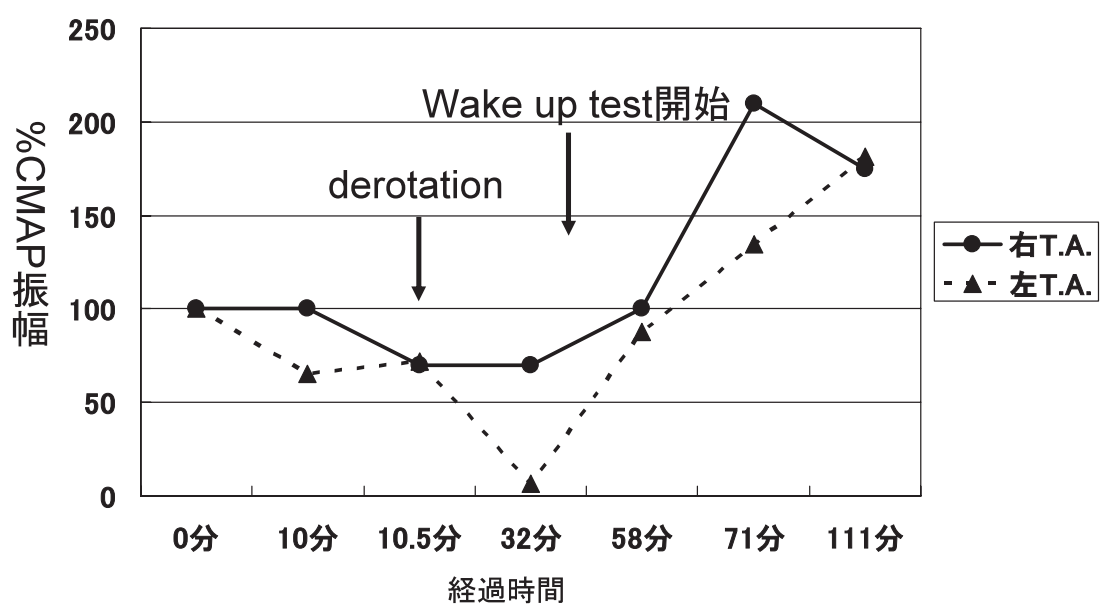

図 3 : 術中の CMAP の振幅の経時的変化. 実線は右の TA から導出した CMAP の振幅の变化, 点線は左の TA から導出した CMAP の振幅 の変化を示す. Wake up test 開始後に振幅は改善している.

考察

CMAP の術中モニタリングでの有用性：辻ら ${ }^{13)}$ は脊 柱側弯症 102 例に CMAP を施行し電位の消失した 4 例中 3 例に一過性神経脱落症状を認め, 側弯症手術で の有用性を述べている。 Nakagawa ら ‘） CMAP は脊䯣の虚血や圧迫障害に他のモニタリング法に比し て sensitive なので運動機能のモニターに好ましいと 述べている。しかし CMAP の減少や消失は必ずしも 術後の運動機能を反映してなかったと報告している.

CMAP の critical point について四宮 ${ }^{10)}$ は潜時の 10 \%の遅延，あるいは $\mathrm{CMAP}$ の消失が適当と述べてい る。また伊藤ら ${ }^{2)}$ は春䯣䯣内腫崵摘出術で Amplitude 50\%以上の低下ないし latensy の 10\%遅延を critical point としている. 本研究では術後の運動障 害を避けるべくAmplitude50\%以上の低下を critical point として採用した。

術前脊髄の偏位と CMAP の変化：春柱管内の脊䯣の 偏位とモニタリングの電位変化の関係について鎌田 ら ${ }^{3)}$ は鈴木の分類の grade が高いほど電位の变化が 多かったと報告している．Maruta ら ${ }^{6)}$ は脊䯣の回旋 は血流や神経活動に障害を与える可能性を指摘してい る.また rod rotation manoeuvreでは頂椎の回旋が 悪化することがあり，特に over rotation type は虚 血などの障害の危険性が高いと警告している。本研究
の症例 1 は鈴木の分類 grade III, Maruta の分類の reverse rotation type であったが, derotation 後 20 分で CMAP が低下し術後両側大腿痛を認めていた。 他の reverse rotation type 2 例でも derotation 後に CMAP の振幅が片側性に低下し術後に大腿の知覚障 害を認めている。 Reverse rotation type では derotation にて脊䯣の回旋が生じて血流障害をきた した可能性が考えられる. しかし何の矯正操作の緩和 操作なく改善しており, 何らかの機序で血流の再開通 が起こったのかむしれない，さらに片側性に CMAP が低下したことも疑問である。 Pateder と Kostuik ${ }^{9)}$ は成人の脊柱変形矯正手術 407 例中 $2.9 \%$ に腰神経根 障害が生じたと報告している。従って片側のみの CMAP の振幅の低下は神経根障害の可能性む否定で きない

術中 CMAP 変化と術中の対応について：本研究では CMAP の変化之術後神経障害の関連は不明であった。 しかし今後 CMAP 振幅 50\%以上の低下をきたした場 合は術後神経障害を回避すべく対応を考えるべきであ る。対応としてまずは直前の矯正操作の解除ないし緩 和が必要である。それであ改善なければ Wake up test を麻醉科に依頼することも躊躇すべきではない． 鎌田ら ${ }^{3)}$ は椎弓切除や椎弓根切除を提唱しているが手 術侵襲の問題むあり Wake up test 後の結果で考慮す べきである. 


\section{結語}

(1) 特発性側弯症 7 例に対して CMAP を利用した春 髄モニタリングを行った。

(2) Derotation で 1 例は両側性に，3 例は片側性に 振幅が低下した。Compression で 3 例が片側性 に低下した。

(3) 矯正操作による脊䯣の血流障害を反映した可能性 がある。

(4) 振幅の $50 \%$ 以上の低下が続くときは Wake up test の施行は躊躇すべきではない.

\section{参 考 文 献}

1）今井克己：側弯症手術における脊䯣誘発電位を用いた 術中春檤モニタリング法の臨床的研究。日整会誌，62： 511-521, 1988 .

2）伊藤全哉ら：春䯙随内腫瘍摘出術への運動路モニタリ ング (Compound Muscle Action Potential) の有用性. 日本脊椎脊髄病学会雑誌，17：233，2006。

3）鎌田修博ら：脊柱側弯症手術における術中脊髄モ二夕 リングの検討一波形の変化と術中の対応について。整形 外科, $50: 249-254,1999$.

4) King, H. A., et al. : The selection of fusion levels in thoracic idiopathic scoliosis. J. Bone Joint Surg.,
65-A : 1302-1313, 1983.

5）村上正純ら：脊柱側弯症手術における術中脊㖪モ二タリ ング. 脊椎脊䯣, $2: 421-427,1989$.

6) Murata, T., et al. : Rotation of the spinal cord in idiopathic scoliosis. J. Bone Joint Surg. Br., 86 : 220-224, 2004.

7) Nakagawa, Y., et al. : Discrepancy between decrease in the amplitude of compound muscle action potential and loss of motor function caused by ischenmic and compressive insults to the spinal cord. J. Orthop. Sci., $7: 102-110,2002$.

8）野原 裕：ISOLA 法之肋骨切除術. 新 OS NOW No.7 第 1 版 最新の脊椎外科, pp.87-93. 岩本幸英, 東京, メジカルビュー社, 2000.

9) Pateder, B. P., Kostuik, J. P. : Lumbar nerve root palsy after adult spinal deformity surgery. Spine, 30 : 1632-1636, 2005

10）四宮謙一：術中脊䯣モニタリング 各種誘発電位検査 法の比較。臨床脳波，42：353-359，2000.

11）飛田俊幸：側彎症手術中の春䯣機能モニタリング. Lisa, 10 : 320-324, 2003.

12）辻 太一ら：春柱変形手術における MEPs 利用の試み. 春柱变形, $17: 29-33,2002$.

13）辻 太一ら：春柱変形矯正手術に㧍ける CMAP モ二 タリングー当院の現状より一. 日本春椎春䯣病学会䧴誌, $17: 426,2006$ 